\title{
Convergent point of $G$-type nonexpansive mapping with graph
}

\author{
D.P. Shukla ${ }^{1}$ and Vivek Tiwari ${ }^{2 *}$ \\ ${ }^{1}$ Govt. Science College Rewa (M.P.) 486001, India \\ ${ }^{2}$ Sharda Mahavidyalya Sarlanagar Maihar satna (M.P.) 485772, India \\ Affiliated to A.P.S. University, Rewa (M.P.) 486003, India
}

Available online at: www.isroset.org

Received: 18/Sept/2018, Accepted:14/Oct/2018, Online: 31/Oct/2018

Abstract- In this paper, we prove some weak and strong convergence of a sequence $\left\{x_{n}\right\}$ generated by the Abbas at el. techniques to some common fixed points of $G$-type nonexpansive mappings defined on Banach space with graph.

Keywords- Fixed point, $G$-nonexpansive mappings, Abbas et al., Banach space, directed graph.

\section{INTRODUCTION}

Banach proved a noteworthy and instance outcomes result is said to be a Banach contraction principle. Because of it's fruitful results, it has been generalized in various areas. The present version of the theorem was given in Banach space by using graph and it's property. Jachymski [1] provide a generalization of the Banach contraction principle to metric space with a graph. Aleomraninejad et al. [2] also give various iterative processes for G-nonexpansive and $G$-contractive mappings on graphs. Alfuraidan [4] provide a new definition of G-contraction and got sufficient conditions for existence of fixed points on a metric space for multivalued function included graphs property. Tiammee et al. [6] proved Browder's convergence theorem for $G$ nonexpansive mapping in a Banach space with graphs and their property.

Inspired by all references, the author proves strong and weak convergence theorems for $G$-type nonexpansive mapping using Abbas at el. iteration generated from any arbitrary $x_{0}$ in closed convex subset of a uniformly convex Banach space $X$ with a graph.

\section{PRELIMINARIES}

In this part, we overview some basic graph notations, terminology and required outcomes.

Let $(X, d)$ be a metric space and $\omega=\{(x, x): x \in X\}$. Now assume a directed graph

$G=(V, E)$ where $V$ is the set of vertices of graph and $E$ is the set of edges of graph contains all loops. Now let the graph $G$ has no parallel edges. Then $G=(V, E)$ by assigning to each edge the distance between it's vertices, $G$ treated as weighted graph.

Definition 2.1 The inverse of a graph $G$ is obtained from $G$ by reversing the direction of edges and it's represented by $G^{-1}$, and numerically defined as follows:

$$
E\left(G^{-1}\right)=\{(x, y) \in X \times X:(y, x) \in E(G)\}
$$

Definition 2.2 Let $x$ and $y$ be the vertices of graph $G$. A path in $G$ form $x$ to $y$ of length $D(D \in D \cup\{0\})$ is sequence $\left\{x_{n}\right\}_{i=0}^{N}$ of $D+1$ vertex for which

$$
x_{0}=x, x_{N}=y \text { and }\left(x_{i}, x_{i+1}\right) \in E \text { for } i=0,1, \ldots D-1 .
$$

Definition 2.3 A graph $\mathrm{G}$ is called connected graph iff there is a path between any two vertices of the graph $G$.

Definition 2.4 A graph $G=(V, E)$ is called transitive if, for any $p, q, r \in V$ such that $(p, q)$ and $(q, r) \in E$ then we have $(p, r) \in E$. 
Definition 2.5 Let $C$ be nonempty convex subset of a Banach space $X$ and $G=(V, E)$ is a directed graphs such that $V=C$, then a mapping $T: C \rightarrow C$ is $G$-nonexpansive ([3], Definition 2.3 (iii)) if it satisfies following conditions:

(i) $\quad T$ is edge preserving.

(ii) $\quad\|T x-T y\| \leq\|x-y\|$, where $(x, y) \in E$ for any $x, y \in C$.

Definition 2.6 [7] Let $C$ be nonempty closed convex subset of a real uniformly convex Banach space $X$. The mappings $T_{i}(i=1,2)$ on $C$ are said to satisfy condition B if there exists increasing function $f:[0, \infty) \rightarrow[0, \infty)$ with $f(0)=0$ and $f(r)>0 \forall r>0$ such that $\forall x \in C$.

$$
\max \left\{\left\|x-T_{1}\right\|,\left\|x-T_{2} x\right\|\right\} \geq f(d(x, F)),
$$

Where $F=F\left(T_{1}\right) \cap F\left(T_{2}\right)$ and $F\left(T_{i}\right)(i=1,2)$ are the sets of fixed points of $T_{i}$.

Definition 2.7: A Banach space $X$ is said to satisfy Opial property if the following inequality holds for any distinct elements $x$ and $y$ in $X$ and for each sequence $\left\{x_{n}\right\}$ weakly convergent to $x$ :

$\lim _{n \rightarrow \infty} \lim \left\|x_{n}-x\right\|<\lim _{n \rightarrow \infty} \inf \left\|x_{n}-y\right\|$.

Definition 2.8 Let $X$ be a Banach space, A mapping $T$ with domain $D$ and range $R$ in $X$ is demiclosed at 0 if, for any sequence $\left\{x_{n}\right\}$ in $D$ such that $\left\{x_{n}\right\}$ converges weakly to $x \in D$ and $\left\{T x_{n}\right\}$ converges to strongly to 0 , we have $T_{x}=0$.

Lemma 2.9 [8] Let $X$ be a uniformly convex Banach space and $\left\{\alpha_{n}\right\}$ a sequence in $[\delta, 1-\delta]$ for some $\delta \in(0,1)$. Suppose that sequences $\left\{x_{n}\right\}$ and $\left\{y_{n}\right\}$ in $X$ are such that $\limsup _{n \rightarrow \infty}\left\|x_{n}\right\| \leq c$, $\limsup _{n \rightarrow \infty}\left\|y_{n}\right\| \leq c$ and $\limsup _{n \rightarrow \infty}\left\|\alpha x_{n}+\left(1-\alpha_{n}\right) y_{n}\right\|=$ $c$ for some $c \geq 0$. Then $\lim _{n \rightarrow \infty}\left\|x_{n}-y_{n}\right\|=0$.

Lemma 2.10 ([9]) Let $X$ be a Banach space, and $R>1$ be a fixed number, then $X$ is uniformly convex iff there exists a continuous, strictly increasing and convex function g: $[0, \infty] \rightarrow[0, \infty)$ with $\mathrm{g}(0)=0$ such that

$$
\|\lambda x+(1-\lambda) x y\|^{2} \leq \lambda\|x\|^{2}+(1-\lambda)\|\lambda\|^{2}-\lambda(1-\lambda) g(\|x-y\|)
$$

For all $x, y \in B_{R}(0)=\{x \in X:\|x\| \leq R\}$ and $\lambda \in[0,1]$.

Lemma 2.11([10]) Let $X$ be a Banach space that satisfies Opial condition, and let $\left\{x_{n}\right\}$ be a sequence in $X$. Let $x, y$ in $X$ be such that $\lim _{n \rightarrow \infty}\left\|x_{n}-x\right\|$ and $\lim _{n \rightarrow \infty}\left\|x_{n}-y\right\|$ exist. If $\left\{x_{n}\right\}$ and $\left\{x_{n_{k}}\right\}$ are subsequence of $\left\{x_{n}\right\}$ that converge weakly to $x$ and $y$ then $x=y$.

\section{MAIN RESULTS}

In this section, we let $C$ be a nonempty closed convex subset of a Banach space $X$ endowed with a directed graph $G=(V, E)$ such that $V=C$ and $\mathrm{E}$ is convex. We also take that the graph $G=(V, E)$ is satisfies transitive property. The mapping $T i(i=1,2,3)$ are $G$-nonexpansive mapping from $C$ to $C$ with $F=F\left(T_{1}\right) \cap F\left(T_{2}\right) \cap F\left(T_{3}\right)$. Let $\left\{x_{n}\right\}$ be a sequence generated from arbitrary element $x_{0} \in C$.

$$
\begin{aligned}
& x_{n+1}=\left(1-\alpha_{n}\right) T_{1} y_{n}+\alpha_{n} T_{1} z_{n} \\
& y_{n}=\left(1-\beta_{n}\right) T_{2} x_{n}+\beta_{n} T_{2} z_{n} \\
& z_{n}=\left(1-\gamma_{n}\right) x_{n}+\gamma_{n} T_{3} x_{n}
\end{aligned}
$$

Where $\left\{\alpha_{n}\right\},\left\{\beta_{n}\right\}$ and $\left\{\gamma_{n}\right\}$ are real sequence in $[0,1]$. 
Theorem 3.1 Let $w_{0} \in F$ such that $\left(x_{0}, w_{0}\right),\left(y_{0}, w_{0}\right),\left(z_{0}, w_{0}\right),\left(w_{0}, x_{0}\right),\left(w_{0}, y_{0}\right)$ and $\left(w_{0}, z_{0}\right)$ are in $\mathrm{E}(\mathrm{G})$. $\operatorname{Then}\left(x_{n}, w_{0}\right),\left(y_{n}, w_{0}\right),\left(z_{n}, w_{o}\right),\left(w_{0}, x_{n}\right),\left(w_{0}, y_{n}\right)$ and $\left(w_{0}, z_{n},\right)$, are in $E(G)$.

Proof: We will proof this theorem by three section, with assumption $\left(x_{0}, w_{0}\right),\left(y_{0}, w_{0}\right)$ and $\left(z_{0}, w_{0}\right) \in E(G)$, then we will show by induction that $\left(x_{n}, w_{0}\right),\left(y_{n}, w_{0}\right)$ and $\left(z_{n}, w_{0}\right) \in E(G)$. Then with the assumption $\left(w_{0}, x_{0}\right),\left(w_{0}, y_{0}\right),\left(w_{0}, z_{0}\right) \in E(G)$, we will again prove by induction method that $\left(w_{0}, x_{n}\right),\left(w_{0}, y_{n}\right)$ and $\left(w_{0}, z_{n}\right) \in E(G)$. In last step we combine above two results than by using transitive property of $G$ to get the statement. Let $\left(x_{0}, w_{0}\right),\left(y_{0}, w_{0}\right)$ and $\left(z_{0}, y_{0}\right) \in E(G)$. Then $\left(T_{1} y_{0}, w_{0}\right),\left(T_{2} z_{0}, w_{0}\right)$ and $\left(T_{3} x_{0}, w_{0}\right) \in E(G)$ then since $(i=12,3)$ are edge preserving. By the convexity of $(G)$ $\left(T_{1} y_{0}, w_{0}\right),\left(x_{0}, w_{0}\right) \in E(G)$, we have $\left(x_{1}, z_{0}\right) \in E(G)$. Then by edge- preserving of $T_{2}$, $\left(T_{2} z_{1}, w_{0}\right) \in E(G)$. Simiarly for $T_{3}$. Again by convexity of $E(G)$ and $\left(T_{2} y_{1}, w_{0}\right),\left(y_{1}, w_{0}\right)$ and $\left(T_{3} x_{1}, w_{0}\right),\left(x_{1}, w_{0}\right) \in E(G)$. Next we suppose that $\left(x_{k}, w_{0}\right)$, $\left(y_{k}, w_{0}\right)$ and $\left(z_{k}, w_{0}\right) \in E(G)$.Then $\left(T_{3} x_{k}, w_{0}\right),\left(T_{2} z_{k}, w_{0}\right)$ and $\left(T_{1} y_{k}, w_{0}\right) \in E(G)$. Since $T_{i}(i=1,2,3)$ are edge-preserving. Since $E(G)$ is convex, $\left(x_{k+1}, w_{0}\right) \in E(G)$. Indeed

$$
\alpha\left(T_{1} y_{k}, w_{0}\right)+(1-\beta)\left(x_{k}, w_{0}\right)=\left(\alpha T_{1} y_{k}+(1-\alpha) x_{k}, w_{0}\right)=\left(y_{k+1}, w_{0}\right) \in E(G)
$$

Similarly, since $T_{2}$ and $T_{3}$ are edge-preserving therefore by the convexity of $E(G)$, we get

$$
\begin{aligned}
& \beta\left(T_{2} z_{k}, w_{0}\right)+(1-\beta)\left(x_{k+1}, w_{0}\right)=\left(\beta T_{2} z_{k+1}+(1-\beta) x_{k+1}, w_{0}\right)=\left(z_{k+1}, w_{0}\right) \in E(G) \\
& \gamma\left(T_{3} x_{k}, w_{0}\right)+(1-\gamma)\left(x_{k+2}, w_{0}\right)=\left(\gamma T_{3} x_{k+1}+(1-\gamma) x_{k+2}, w_{0}\right)=\left(x_{k+1}, w_{0}\right) \in E(G)
\end{aligned}
$$

Hence by the induction $\left(x_{n}, w_{0}\right),\left(y_{n}, w_{0}\right)$ and $\left(z_{n}, w_{0}\right) \in E(G)$. now using similar argument we can show that $\left(w_{0}, x_{n}\right)$, $\left(w_{0}, y_{n}\right)$ and $\left(w_{0}, z_{n}\right) \in E(G)$. Therefore $\left(x_{n}, z_{n}\right) \in E(G)$ by the transitivity of $\mathrm{G}$.

Theorem 3.2 Let $w_{0} \in F$. Suppose $\left(x_{0}, w_{0}\right),\left(y_{0}, w_{0}\right),\left(z_{0}, w_{0}\right),\left(w_{0}, x_{0}\right),\left(w_{0}, y_{0}\right)$ and $\left(w_{0}, z_{0}\right) \in E(G)$ for arbitrary $x_{0}$ in $C$. Then $\lim _{n \rightarrow \infty}\left\|x_{n}-z_{0}\right\|$ exists.

\section{Proof:}

$$
\begin{aligned}
\left\|x_{n+1}-w_{0}\right\|=\| & \left(1-\alpha_{n}\right) T_{1} y_{n}+\alpha_{n} T_{1} z_{n}-w_{0} \| \\
& \leq\left(1-\alpha_{n}\right)\left\|T_{1} y_{n}-w_{0}\right\|+\alpha_{n}\left\|T_{1} z_{n}-w_{0}\right\| \\
& \leq\left(1-\alpha_{n}\right)\left\|\left(1-\beta_{n}\right) T_{2} x_{n}+\beta_{n} T_{2} z_{n}-z_{0}\right\|+\alpha_{n}\left\|\left(1-\gamma_{n}\right) x_{n}+\gamma_{n} T_{3} x_{n}-w_{0}\right\| \\
& \leq\left(1-\alpha_{n}\right)\left(1-\beta_{n}\right)\left\|T_{2} x_{n}-w_{0}\right\|+\left(1-\alpha_{n}\right) \beta_{n}\left\|T_{2} z_{n}-w_{0}\right\|+ \\
& \quad \alpha_{n}\left(1-\gamma_{n}\right)\left\|x_{n}-w_{0}\right\|+\alpha_{n} \gamma_{n}\left\|T_{3} x_{n}-w_{0}\right\| \\
& \leq\left(1-\alpha_{n}\right)\left(1-\beta_{n}\right)\left\|T_{2} x_{n}-w_{0}\right\|+\left(1-\alpha_{n}\right)\left(1-\gamma_{n}\right) \beta_{n}\left\|x_{n}-w_{0}\right\|+ \\
& \quad\left(1-\alpha_{n}\right) \beta_{n} \gamma_{n}\left\|x_{n}-x_{0}\right\|+\alpha_{n}\left(1-\gamma_{n}\right)\left\|x_{n}-x_{0}\right\|+\alpha_{n} \gamma_{n}\left\|T_{3} x_{n}-w_{0}\right\| \\
& =\left\|x_{n}-w_{0}\right\|
\end{aligned}
$$

Thus $\lim _{n \rightarrow \infty}\left\|x_{n}-w_{0}\right\|$ exists. Hence the sequence $\left\{x_{n}\right\}$ is bounded.

Theorem 3. 3 If $X$ is uniformly convex $\left\{\alpha_{n}\right\},\left\{\beta_{n}\right\}$ and $\left\{\gamma_{n}\right\} \subset[\delta ; 1-\delta]$ for some $\delta \in(0,1 / 3)$

and $\left(x_{0}, w_{0}\right),\left(y_{0}, w_{0}\right),\left(z_{0}, w_{0}\right),\left(w_{0}, x_{0}\right)\left(w_{0}, y_{0}\right)$ and $\left(w_{0}, z_{0}\right) \in E(G)$ for arbitrary $x_{0}$ in $\mathrm{c}$ and $z_{0} \in F$, then

$\lim _{n \rightarrow \infty}\left\|x_{n}-T_{1} x_{n}\right\|=\lim _{n \rightarrow \infty}\left\|x_{n}-T_{2} x_{n}\right\|=\lim _{n \rightarrow \infty}\left\|x_{n}-T_{3} x_{n}\right\|=0$.

Proof: Let $w_{0} \in F$. Then by the boundedness of $\left\{x_{n}\right\},\left\{T_{2} z_{n}\right\}$ and $\left\{T_{3} x_{n}\right\}$ there exists $r>0$, such that $\left(x_{n}-w_{0}\right),\left(y_{n}-w_{0}\right)$ and $\left(z_{n}-w_{0}\right) \in B_{r}(0)$ for all $n \geq 1$. Put $c=\lim _{n \rightarrow \infty}\left\|x_{n}-w_{0}\right\|$. If $\mathrm{c}=0$, then by the $G$-nonexpansiveness of $T_{i}(i=1,2,3)$ we have 
$\left\|x_{n}-T_{i} x_{n}\right\| \leq\left\|x_{n}-w_{0}\right\|+\left\|w_{0}-T_{i} x_{n}\right\| \leq\left\|x_{n}-w_{0}\right\|+\left\|w_{0}-x_{n}\right\|$

Therefore the result follows that $c>0$. Hence by lemma 2.10 together with the $G$-nonexpansiveness of $T_{2}$ and $T_{3}$, we have

$$
\begin{aligned}
\left\|y_{n}-w_{0}\right\|^{2}= & \left\|\left(1-\beta_{n}\right) T_{2} x_{n}+\beta_{n} T_{2} z_{n}-w_{0}\right\|^{2} \\
& =\left\|\beta_{n}\left(T_{2} z_{n}-w_{0}\right)+\left(1-\beta_{n}\right)\left(T_{2} x_{n}-w_{0}\right)\right\|^{2} \\
& \leq \beta_{n}\left\|T_{2} z_{n}-w_{0}\right\|^{2}+\left(1-\beta_{n}\right)\left\|\left(T_{2} x_{n}-w_{0}\right)\right\|^{2}-\beta_{n}\left(1-\beta_{n}\right) \mathrm{g}\left(\left\|T_{2} z_{n}-z_{n}\right\|\right. \\
& \leq \beta_{n}\left\|z_{n}-w_{0}\right\|^{2}+\left(1-\beta_{n}\right)\left\|x_{n}-w_{0}\right\|^{2} \\
& \leq \beta_{n}\left\{\left\|\left(1-\gamma_{n}\right) x_{n}+\gamma_{n} T_{3} x_{n}-w_{0}\right\|^{2}\right\}+\left(1-\beta_{n}\right)\left\|x_{n}-w_{0}\right\|^{2} \\
& \leq \beta_{n}\left\|x_{n}-w_{0}\right\|^{2}+\left(1-\beta_{n}\right)\left\|x_{n}-w_{0}\right\|^{2} \\
& =\left\|x_{n}-w_{0}\right\|^{2} .
\end{aligned}
$$

and

$$
\begin{aligned}
\left\|z_{n}-w_{0}\right\|^{2}= & \left\|\left(1-\gamma_{n}\right) x_{n}+\gamma_{n} T_{3} x_{n}-w_{0}\right\|^{2} \\
& =\left\|\gamma_{n}\left(T_{3} x_{n}-w_{0}\right)+\left(1-\gamma_{n}\right)\left(x_{n}-w_{0}\right)\right\|^{2} \\
& \leq \gamma_{n}\left\|T_{3} x_{n}-w_{0}\right\|^{2}+\left(1-\gamma_{n}\right)\left\|\left(x_{n}-w_{0}\right)\right\|^{2}-\gamma_{n}\left(1-\gamma_{n}\right) \mathrm{g}\left(\left\|T_{3} x_{n}-x_{n}\right\|\right. \\
& \leq \gamma_{n}\left\|x_{n}-w_{0}\right\|^{2}+\left(1-\gamma_{n}\right)\left\|x_{n}-w_{0}\right\|^{2} \\
& =\left\|x_{n}-w_{0}\right\|^{2} .
\end{aligned}
$$

Thus we have

$$
\lim _{n \rightarrow \infty}\left\|y_{n}-w_{0}\right\| \leq \lim _{n \rightarrow \infty}\left\|x_{n}-w_{0}\right\| \leq \lim _{n \rightarrow \infty}\left\|z_{n}-w_{0}\right\|
$$

Now we have also

$$
\begin{aligned}
\left\|x_{n+1}-w_{0}\right\|^{2}= & \left\|\left(1-\alpha_{n}\right) T_{1} y_{n}+\alpha_{n} T_{1} z_{n}-w_{0}\right\|^{2} \\
& =\left\|\alpha_{n}\left(T_{1} z_{n}-w_{0}\right)+\left(1-\alpha_{n}\right)\left(T_{1} y_{n}-w_{0}\right)\right\|^{2} \\
\leq & \alpha_{n}\left\|T_{1} z_{n}-w_{0}\right\|^{2}+\left(1-\alpha_{n}\right)\left\|\left(T_{1} y_{n}-w_{0}\right)\right\|^{2}-\alpha_{n}\left(1-\alpha_{n}\right) \mathrm{g}\left(\left\|T_{2} z_{n}-T_{1} y_{n}\right\|\right. \\
\leq & \left\|x_{n}-w_{0}\right\|^{2}-\delta^{2} \mathrm{~g}\left(\left\|T_{1} y_{n}-x_{n}\right\|\right)
\end{aligned}
$$

Thus

$\delta^{2} \mathrm{~g}\left(\left\|T_{1} y_{n}-x_{n}\right\|\right) \leq\left\|x_{n}-x_{0}\right\|^{2}-\left\|x_{\mathrm{n}+1}-w_{0}\right\|^{2}$.

Implies that $\lim _{n \rightarrow \infty} \mathrm{g}\left(\left\|T_{1} y_{n}-w_{0}\right\|\right)=0$ and $\mathrm{g}$ is strictly increasing and continuous at 0 .

$\lim _{n \rightarrow \infty}\left\|T_{1} y_{n}-w_{0}\right\|=0$.

Since $T_{1}$ is $G$-nonexpansive, then we have

$\left\|x_{n}-w_{0}\right\| \leq\left\|x_{n}-T_{1} y_{n}\right\|+\left\|T_{1} y_{n}-T_{1} w_{0}\right\| \leq\left\|x_{n}-T_{1} y_{n}\right\|+\left\|y_{n}-w_{0}\right\|$

Now taking lim inf yields

$\lim _{n \rightarrow \infty}\left\|y_{n}-w_{0}\right\| \geq c$. 
Hence we have

$\lim _{n \rightarrow \infty}\left\|y_{n}-w_{0}\right\|=c$.

Since

$\lim _{n \rightarrow \infty}\left\|\beta_{n}\left(T_{2} x_{n}-w_{0}\right)+\left(1-\beta_{n}\right)\left(x_{n}-w_{0}\right)\right\|=\lim _{n \rightarrow \infty}\left\|y_{n}-w_{0}\right\|=c$

and

$\lim _{n \rightarrow \infty}\left\|\gamma_{n}\left(T_{3} x_{n}-w_{0}\right)+\left(1-\gamma_{n}\right)\left(x_{n}-w_{0}\right)\right\|=\lim _{n \rightarrow \infty}\left\|z_{n}-w_{0}\right\|=c$.

and $\lim _{n \rightarrow \infty} \sup \left\|T_{2} x_{n}-w_{0}\right\| \leq c$,

Similarly

$\lim _{n \rightarrow \infty} \sup \left\|T_{3} x_{n}-w_{0}\right\| \leq c$.

So, by lemma 2.9 , we have

$\lim _{n \rightarrow \infty} \sup \left\|T_{2} x_{n}-x_{n}\right\|=0$.

$\lim _{n \rightarrow \infty} \sup \left\|T_{3} z_{n}-z_{n}\right\|=0$.

by the $G$-nonexpansiveness of $T_{1}, T_{2}$ and $T_{3}$ together with

$\left\|x_{n}-y_{n}\right\| \leq\left\|T_{2} z_{n}-x_{n}\right\| \leq\left\|T_{3} x_{n}-x_{3}\right\|$, we have

$$
\begin{aligned}
\left\|T_{1} x_{n}-x_{n}\right\| & \leq\left\|T_{1} x_{n}-T_{1} z_{n}\right\|+\left\|T_{1} z_{n}-T_{1} y_{n}\right\|+\left\|T_{1} y_{n}-x_{n}\right\| \\
& \leq\left\|x_{n}-z_{n}\right\|+\left\|z_{n}-y_{n}\right\|+\left\|y_{n}-x_{n}\right\| \\
& \leq\left\|T_{3} x_{n}-z_{n}\right\|+\left\|T_{2} z_{n}-y_{n}\right\|+\left\|T_{1} y_{n}-x_{n}\right\|
\end{aligned}
$$

From (i), (ii) and (iii), we have

$$
\left\|T_{1} x_{n}-x_{n}\right\|=0
$$

Hence Theorem is proved.

Theorem 3.4 Let $X$ satisfies the opial's condition that $\left(x_{0}, w_{0}\right),\left(y_{0}, w_{0}\right),\left(z_{0}, w_{0}\right) \in E(G)$ for $w_{0} \in F$ and arbitrary $x_{0} \in C$. Then $I-T_{i}(i=1,2,3)$ are demiclosed.

Proof: Assume that $\left\{x_{n}\right\}$ is a sequence in $\mathrm{C}$ that converges weakly to $\mathrm{q}$ from theorem 3.3 , we have $\lim _{n \rightarrow \infty}\left\|x_{n}-T_{i} x_{n}\right\|=0$.

Then by contradiction that $q \neq T_{i} q$, then by opial's condition we have

$$
\begin{aligned}
\lim _{n \rightarrow \infty} \sup \left\|x_{n}-q\right\|< & \lim _{n \rightarrow \infty} \sup \left\|x_{n}-T_{i} q\right\| \\
& \leq \lim _{n \rightarrow \infty} \sup \left(\left\|x_{n}-T_{i} x_{n}\right\|+\left\|T_{i} x_{n}-T_{i} q\right\|\right) \\
& \leq \lim _{n \rightarrow \infty} \sup \left\|x_{n}-q\right\|, \text { a contradiction. }
\end{aligned}
$$

Hence $T_{i} q=q$.

So the conclusion holds. 


\section{CONCLUSION}

This paper presents the calculation of fixed point by the use of graph and it's properties. It also helps to calculate fixed point by various properties of graphs in the future with different aspects.

\section{References}

[1] Jachymski, J: The contraction principle for mappings on a metric space with a graph. Proc. Am. Math. Soc.136, 1359-1373 (2008).

[2] Aleomraninejad, SMA, Rezapour, S, Shahzad, N: Some fixed point result on a metic space with a graph. Topol. Appl. 159, 659-663 (2012).

[3] Alfuraidan, MR, Khasmi, MA: Fixed points of monotone nonexpansive mappings on a hyperbolic metric space with a graph. Fixed point theory Appl. (2015).

[4] Alfuraidan, MR: Fixed points of monotone multivalued mappings on a metic space with a graph J. inequal. Appl. (2015).

[5] Alfuraidan, MR: Fixed points of monotone nonexpansive mapping with a graph, fixed point theory Appl. (2015).

[6] Tiammee, J, Kaehao, A, Suantai, S,On Browder's convergence theorem and Halpern iteration process for G-nonexpansive mappings in Hilbert spaces endowed with graph. Fixed point Theory Appl. (2015).

[7] Shahzad, N, Al-Dubiban, R; Approximating common fixed points of nonexpansive mappings in Banach spaces Georgian Math. J. 13 (3), 529-537 (2006).

[8] Schu, J: weak and strong convergence to fixed points of asymptotically nonexpansive mappings. Bull. Aust. Math. Soc. 43 (1), 153-159 (1991).

[9] Xu, HK: Inequalities in Banach spaces with applications. Nonlinear anal.16 (12), 1127-1138 (1991).

[10] Suantai, S: weak and strong convergence criteria of Noor iterations for asymptotically nonexpansive mappings J. Math. Anal. Appl. 331, 506517 (2005).

\section{AUTHORS PROFILE:}

Prof. Dr. D.P.Shukla is a professor and Head, department of Mathematics and computer science, Govt. P.G. Science college Rewa (M.P.) affiliated with Awadhesh Pratap Singh university Rewa (M.P.), India. He has more than 25 year Research and teaching experience in the field of pure mathematics. His major research interest is in fixed point theory, functional analysis, measure theory etc. and has more than 150 articles in the national and international journals.

Mr. Vivek Tiwari is research scholar of mathematics under the supervision of Prof. D.P. Shukla. He is assistant professor of Mathematics at Sharda Mahavidyalaya, Sarlangar, Maihar, disst. Satna (M.P.), India runs by B.K. Birla group of companies. His area of research in fixed point theory and he has presented research paper in various national and international conferences. 